\title{
PROBLEMÁTICA SOCIOAMBIENTAL DA ÁREA URBANA DE ITAPETIM (PE): O ESPAÇO, A SOCIEDADE E O AMBIENTE
}

\author{
SOCIAL ENVIRONMENTAL PROBLEMS OF URBAN \\ AREA OF ITAPETIM (PERNAMBUCO, BRAZIL): SPACE, \\ SOCIETY AND THE ENVIRONMENT
PROBLEMAS SOCIALES Y AMBIENTALES DE LA ÁREA
URBANA DE ITAPETIM (PERNAMBUCO, BRASIL):
EL ESPACIO, LA SOCIEDAD Y EL AMBIENTE

\begin{abstract}
Amanda de Lira Freitas
Mestranda no curso de Ciências Florestais da Unidade Acadêmica de Engenharia Florestal/Centro de Saúde e Tecnologia Rural/Universidade Federal de Campina Grande (UAEF/CSTR/UFCG). E-mail: amanda.27.lira@gmail.com

\section{João Batista Alves}

Professor Doutor da Unidade Acadêmica de Engenharia Florestal/Universidade Federal de Campina Grande (UAEF/UFCG).E-mail: alvesjb@uol.com.br
\end{abstract}

\section{Resumo}

O presente artigo teve por objetivo verificar a ocorrência dos problemas socioambientais na área urbana da cidade de Itapetim, no estado de Pernambuco, bem como a relação destas ocorrências com o conhecimento ambiental e as relações que a sociedade estabelece com o espaço urbano. Para tanto, se estabeleceu como procedimento metodológico o levantamento de campo de ocorrência dos problemas ambientais observados na área urbana, com registro em planilhas específicas. Para elucidar as relações que se estabelecem entre espaço, sociedade e questões ambientais, utilizou-se um questionário. As principais ocorrências de problemas ambientais consideradas mais significantes estão relacionadas aos resíduos sólidos, seguidos, terrenos baldios, poluição visual e arborização urbana. Os gestores e administradores dessa cidade não apresentam projetos para a conservação/preservação do seu meio ambiente, e suas escolas não apresentam programas de educação ambiental. A população não demonstrou saber e nem procurar se familiarizar com a problemática ambiental da cidade, salvo algumas exceções. O uso do espaço urbano, em Itapetim, está em desarmonia.

Palavra-Chave: espaço urbano, meio ambiente, cidade, sociedade, Itapetim/PE.

\section{Abstract}

The present article had as objective verify the occurrence of social environmental problems in the urban area of the city of Itapetim, in Pernambuco state (Brazil), and the relationship of these occurrences with environmental knowledge and relationships that the society

D 
establishes with the urban space. To this end, it was established as methodological procedure the occurrence of field survey of environmental problems observed in the urban area, with registration in specific spreadsheets. To elucidate the relationships established between space, society and environmental issues from a specific questionnaire. The main occurrences of environmental problems considered most significant are related to solid waste, followed by vacant lands, visual pollution and urban tree planting. Managers and administrators of the city do not present projects for conservation/preservation of the environment, and their schools do not have environmental education programs. The population did not show knowledge nor sought to become familiar with the environmental problems of the city, only a few exceptions. The use of urban space is in disharmony in Itapetim.

Keyword: urban space, environment, city, society, Itapetim (PE/Brazil).

\section{Resumen}

Este artículo tuvo como objetivo verificar la ocurrencia de problemas socioambientales en el área urbana de la ciudad de Itapetim, en el estado de Pernambuco (Brasil), y la relación de estos hechos con el conocimiento ambiental y relaciones que la sociedad establece con el espacio urbano. Con este fin, se ha establecido como procedimiento metodológico el levantamiento de campo de los problemas ambientales en el área urbana, con el registro en hojas de cálculo específicas. Para aclarar las relaciones que se establecen entre el espacio, la sociedad y las cuestiones ambientales, se ha utilizado un cuestionario. Las principales ocurrencias de problemas ambientales consideradas importantes están relacionadas con los residuos sólidos, seguidos de terrenos baldíos, contaminación visual y la plantación de árboles urbanos. Los gestores y administradores de la ciudad no presentan proyectos dirigidos a conservación/preservación de su medio ambiente, y sus escuelas no cuentan con programas de educación ambiental. La población no mostró conocimiento y tampoco busca familiarizarse con la problemática ambiental de la ciudad, salvo algunas excepciones. El uso del espacio urbano se encuentra en desarmonía en Itapetim.

Palabras clave: espacio urbano, medio ambiente, ciudad, sociedade, Itapetim (PE/Brasil). 


\section{O espaço e a problemática socioambiental urbana}

A ocupação humana e o uso do espaço natural ocorrem no conjunto da paisagem e no tempo, que estão entrelaçados, formando um contínuo. Contudo, o espaço tem sido esquecido pelas forças econômicas que impõem uma dinâmica de tempo que oculta a questão espacial. Nesse sentido, Rodrigues (1998, p. 7) afirma que "o período moderno caracteriza-se pelo predomínio da metáfora temporal que obscurece a metáfora espacial". Ainda segundo esta autora, "a ocultação do espaço, no período moderno, está relacionada, a que o tempo parece portador de toda a potencialidade de transformação para o bem" (RODRIGUES, 1998, p. 9).

Porém, na perspectiva de Santos (2006, p. 132), “a idéia de que o tempo suprime o espaço provém de uma interpretação delirante do encurtamento das distâncias, com os atuais progressos no uso da velocidade pelas pessoas, coisas e informações". Dessa forma, se esquece de que há um meio natural representado pela "tecnosfera”, fruto da interação homem-natureza, e uma "psicosfera”, específica da cultura humana (SANTOS, 2006, p. 172). Assim, os diferentes espaços de ocupação podem possuir diferentes formas de percepção, e é no meio urbano que os aspectos mencionados se intensificam, sendo este o local onde a maior parte da população e as tecnoestruturas se concentram.

Conforme mencionado, o espaço urbano se torna elemento central da problemática socioambiental. Santos (1988, p. 10) menciona que "o espaço deve ser considerado como um conjunto indissociável de que participam, de um lado, certo arranjo de objetos geográficos, objetos naturais e objetos sociais, e, do outro, a vida que os preenche e os animais, seja a sociedade em movimento". Esse autor concretiza seu pensamento citando que o espaço é "definido como um conjunto indissociável de sistemas de objetos e de sistemas de ações" (SANTOS, 2006, p. 12), e compreende que o espaço é formado por um "conjunto indissociável, solidário e contraditório de sistemas de objetos e sistemas de ações, não considerados isoladamente, mas como o quadro único no qual a história se dá" (SANTOS, 2006, p. 39).

Esse quadro único mencionado por Santos está relacionado às questões sociais e ambientais, e "se a metáfora temporal é predominante no período moderno, a questão ambiental traz à tona, de forma nova, a metáfora espacial" (RODRIGUES, 1998, p. 9). Santos (2016, p. 39) compreende que "os objetos não têm realidade filosófica, isto é, não nos permitem o conhecimento, se os vemos separados dos sistemas de ações. Os sistemas de ações também não se dão sem os sistemas de objetos". Santos afirma, ainda, que

D 
O espaço é hoje um sistema de objetos cada vez mais artificiais, povoado por sistemas de ações igualmente imbuídos de artificialidade, e cada vez mais, tendentes a fins estranhos ao lugar e a seus habitantes. [...] De um lado, os sistemas de objetos condicionam a forma como se dão as ações e, do outro lado, o sistema de ações leva à criação de objetos novos ou se realiza sobre objetos preexistentes. É assim que o espaço encontra a sua dinâmica e se transforma (SANTOS, 2006, p. 39).

De um lado, os sistemas de objetos condicionam a forma como se dão as ações e, do outro lado, o sistema de ações leva à criação de objetos novos ou se realiza sobre objetos preexistentes. É assim que o espaço encontra a sua dinâmica e se transforma. [...] (SANTOS, 2006, p. 39). Essa artificialização da natureza produziu uma dicotomia entre sociedade e natureza, consequência de uma globalização calcada puramente em aspectos econômicos. Isto vem produzindo desigualdades sociais e ambientais. Estes dois elementos desse processo foram denominados por Rodrigues (1998) de "intercâmbio ecologicamente desigual", que não se dá somente no campo da economia, com a subvalorização do trabalho, mas com o uso dos diversos tipos de recursos naturais. Para essa autora, "a contradição entre os dados de progresso econômico e qualidade ambiental e o intercâmbio ecologicamente desigual entre países e regiões mostram que é fundamental construir um paradigma científico que dê conta da realidade". Nesse contexto, muitos dos recursos naturais são usados e não entram na contabilidade pelas chamadas "trocas desiguais", colocando em dúvida o paradigma do desenvolvimento sustentável, pois, "o progresso tido como o avanço científico tecnológico é fundamentalmente problemático" (RODRIGUES, 1998, p. 75-77).

David Harvey (2012) reforça essa questão acerca das características do desenvolvimento geográfico desigual, termo usado por este autor para substituir o termo "globalização". Para ele,

[...] o mundo em qualquer escala particular revela de imediato toda uma série de efeitos e processos que produzem diferenças geográficas nos modos de vida, nos padrões de vida, nos usos dos recursos, nas relações com o ambiente e nas formas políticas e culturais. Essas diferenças geográficas estão sendo perpetuamente reproduzidas, sustentadas, solapadas e reconfiguradas por meio de processos político-econômicos e socioecológicos que ocorrem no momento presente (HARVEY, 2012, p. 110-111).

As contradições da sociedade fazem com que emerja, no espaço, “[...] ao mesmo tempo, mercadorias e territórios desejáveis e vendáveis e mercadorias e territórios indesejáveis" (RODRIGUES, 1998, p. 86). Nesse sentido, esta autora menciona que a problemática ambiental requer releituras de território, e, para isso, levanta uma questão: "como realizar releituras do território que não camuflem? Ocultar as relações sociais e as formas como se dão a apropriação da natureza e de sua exploração é um enorme desafio" (RODRIGUES, 1998, p. 70). 
Os autores supracitados fazem, de forma comum, uma análise crítica das ações humanas frente à natureza e à própria sociedade, em função do status econômico vigente, cujo modelo determina

[...] várias esferas do processo de desenvolvimento, apropriação de recursos e estabelecimento de relações sociais, quase sempre hegemônicos, de modo a influir no constructo do ambiente natural consubstanciado com o ambiente social. Neste sentido, a grande discussão que se estabelece é como se dá o processo de ocupação e desenvolvimento do meio natural e qual a participação da ação social nele verificada (ALVES, 2013, p. 56).

Nessa mesma seara, Ana Fani Carlos menciona que

\begin{abstract}
A análise do lugar, que envolve também a análise da vida cotidiana, pressupõe a superação do entendimento da produção do espaço restrita ao plano econômico, abrindo-se para o entendimento da sociedade em seu movimento mais amplo, como espaço constitutivo da realização da vida humana no seio da produção do espaço em sua dimensão abstrata de mercadoria (CARLOS, 2011, p. 71, grifo da autora).
\end{abstract}

Levando em consideração as questões até então abordadas, é preciso que se faça uma análise do contexto do espaço urbano e a questão ambiental, pois todas as alterações não naturais ocorridas na fauna, flora, solo, recursos hídricos e no ar são consideradas impactos ambientais, e as ocorridas por questões culturais, impactos econômicos e sociais. Esses conjuntos de problemas ambientais somados aos problemas sociais são, contemporaneamente, denominados de "problemas socioambientais", que, muitas vezes, não são percebidos com clareza pela população. O modelo atual de vida das populações (urbano-industrial) é altamente predatório e, ao longo dos anos, tem provocado problemas socioambientais graves, cujos impactos e consequências podem ser comparados aos efeitos de grandes catástrofes naturais ocorridas no decurso dos séculos, conforme foi registrado por diversos autores, entre os quais Dorst (1973).

O somatório do crescimento exponencial da população, modelo de desenvolvimento econômico vigente, junto com questões culturais e a ausência de educação ambiental têm gerado problemas ecológicos que comprometem a capacidade de suporte do planeta (SILVA et al., 2006). Santos (2010) menciona que a migração massiva do campo para as cidades vai ocasionar o crescimento desordenado destas, pois, em especial nos países da América Latina, as cidades não estavam e não estão preparadas para isto. Dessa forma, emergem os problemas socioambientais e os mais diversos tipos de conflitos, devido à grande concentração de pessoas nesse espaço, sem que este esteja preparado.

D

D D Revista da Associação Nacional de Pós-graduação e Pesquisa em Geografia (Anpege).

D D p.6-30, V.15, n.27, mai./ago. 2019. 
Nesse sentido, é preciso refletir sobre a necessidade de se criar e desenvolver sistemas de gestão ambiental dentro dos espaços urbanos, para que neles esteja contido o respeito a todos os direitos dos cidadãos, preservando seu futuro, e para que sua qualidade de vida não seja prejudicada ou que seja, pelo menos, estável (PHILIPPI JR. et al., 1999).

Diversos autores têm tratado da problemática socioambiental urbana nas cidades, e, entre estes, se destacam: Philippi Jr. et al. (1999), Guerra e Cunha (2001), Maricato (2001), Mendonça et al. (2004), Santos (2005), Santos (2010) e Souza (2010). Já Alves et al. (2004) tratam exclusivamente das pequenas cidades do interior do Nordeste brasileiro.

Tanto as grandes quanto as pequenas cidades sofrem o impacto da urbanização descontrolada, no constructo do espaço urbano. Portanto, acredita-se que várias cidades do interior do Brasil (em especial, as do Nordeste brasileiro) ainda precisam de estudos dos problemas ambientais que atingem sua população, a própria natureza e o uso desse espaço.

Refletindo sobre os problemas supracitados, percebe-se que estes também ocorrem na cidade de Itapetim. Dessa forma, este artigo propõe a investigação dessas questões, e a orientação de sua pesquisa foi guiada pela tentativa de responder à seguinte proposição: quais são e como se manifestam os problemas ambientais no espaço urbano da cidade de Itapetim e qual o conhecimento e a percepção dos seus habitantes quanto a estes problemas?

\section{Localização da área de estudo}

Este estudo foi realizado na cidade de Itapetim, no estado de Pernambuco (Figura 1), localizada na microrregião do Pajeú e na macrorregião do Sertão Pernambucano. Sua área territorial é de 408,0 $\mathrm{km}^{2}$. A sede municipal em estudo está a 637 metros de altitude em relação ao nível do mar, tem sua posição geográfica determinada pelo paralelo de $-7^{\circ} 22$ 40.8 da latitude $-37^{\circ} 1125$ de longitude. Seu clima é semiárido quente, com temperaturas variando entre $20^{\circ} \mathrm{C}$ e $36^{\circ} \mathrm{C}$, e o seu bioma é a caatinga. Possui uma população de 13.881 habitantes, sendo que 8.426 estão na zona urbana e 5445, na zona rural. 
Figura 1 - Mapa de localização de Itapetim/PE.

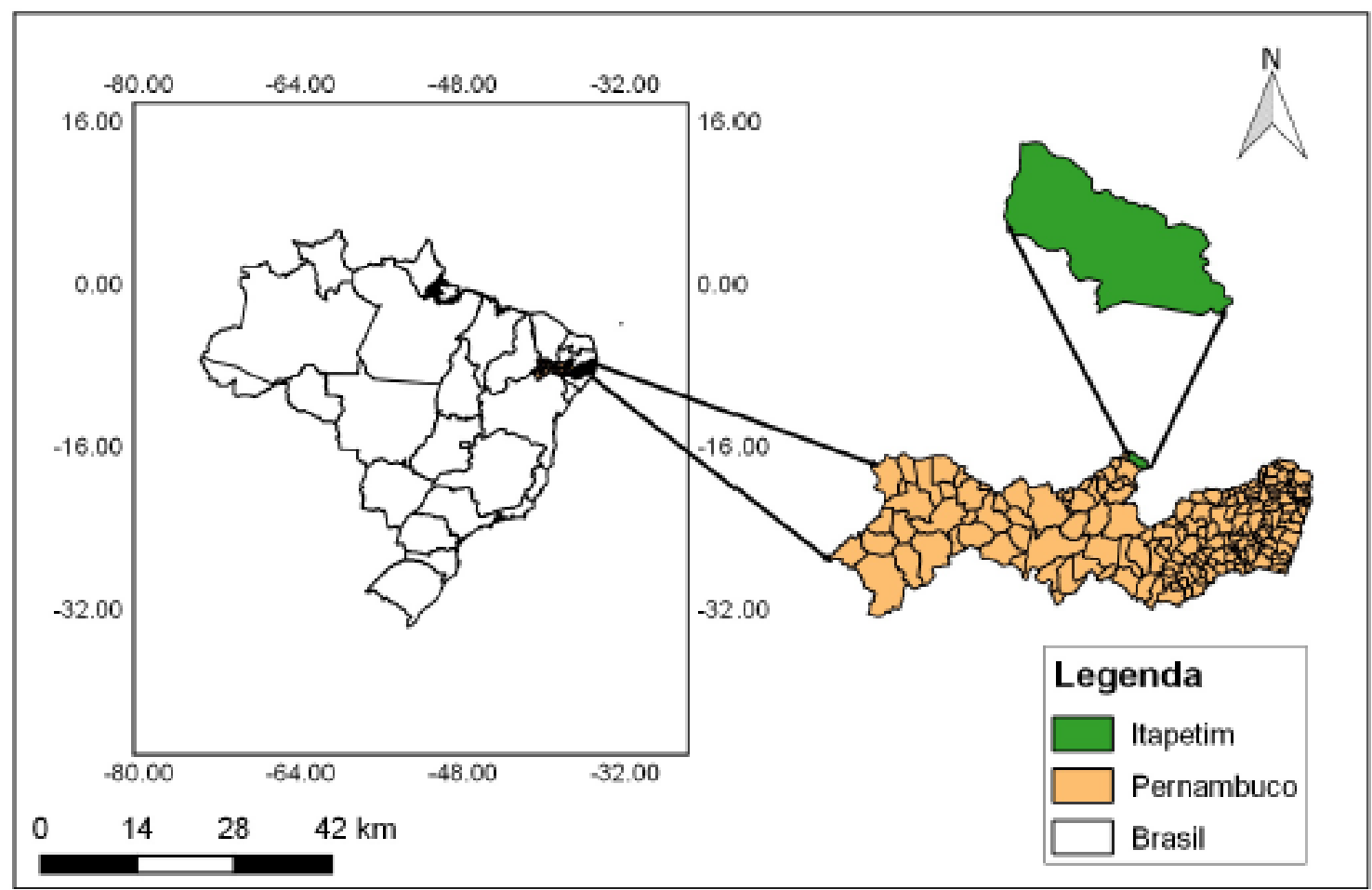

Fonte: Elaborado pelos autores, 2015.

\section{Procedimento de campo para o diagnóstico de problemas ambientais urbanos}

Para a avaliação ambiental da área urbana, foi utilizada a metodologia de observação de campo preconizada por ROCHA (1997) e adaptada por Alves et al. (2004), que consiste em elencar uma série de parâmetros socioambientais (expressos na legenda da Figura 2) que são avaliados ao se percorrer todas as ruas da área urbana, fotografando e registrando, em planilha específica, as ocorrências dos problemas ambientais encontrados. Estes problemas foram, então, classificados em nível de importância, pela quantidade de ocorrências registradas para cada parâmetro observado.

D

D D p.6-30, V.15, n.27, mai./ago. 2019. 


\section{Procedimentos para o diagnóstico do grau de conhecimento sobre a existência e o funcionamento de leis e infraestrutura relacionada a questões ambientais}

As entrevistas realizadas para esta pesquisa consistiram no uso de questionário específico para cada público-alvo, tendo sido entrevistados 70 residentes, 10 vereadores e um representante do poder executivo da Secretaria de Meio Ambiente. Os parâmetros avaliados foram utilizados para se verificar a existência ou não de secretarias, leis e infraestruturas, bem como se estas estavam ou não cumprindo as funções para as quais foram criadas. Poderia existir uma secretaria que constasse no organograma, mas, na realidade, não funcionasse ou realizasse o serviço de forma parcial, assim como leis que existissem, mas que, de fato, não eram cumpridas ou eram cumpridas de forma parcial.

\section{Conhecimento e percepção da população sobre os problemas ambientais da área urbana da cidade}

Para avaliação do grau de conhecimento e de percepção dos problemas socioambientais junto à população de Itapetim, utilizaram-se como instrumentos de investigação questionários com perguntas estruturadas e semiestruturadas. A escolha dos entrevistados foi feita de forma aleatória, sendo entrevistadas 150 pessoas. Para esta avaliação, foi utilizado um conjunto de questões, variando estas desde o entendimento sobre conceitos como poluição, meio ambiente e ecologia até questões sobre os parâmetros avaliados pelo pesquisador, no levantamento de problemas socioambientais nas ruas da cidade, assim como o perfil do entrevistado e a avaliação dos serviços urbanos prestados pela prefeitura.

\section{Resultados e discussão}

Por meio do diagnóstico da cidade de Itapetim, verificou-se a existência de 140 ruas, travessas, avenidas e becos, sendo $1 / 3$ destes sem pavimentação e manutenção em calçamentos e/ou asfalto. Na Figura 2, estão expressas as 1500 ocorrências dos problemas ambientais observados, com base na metodologia proposta, levando-se em consideração o que mencionam Alves et al. (2004) sobre tais problemas, que são "poucos importantes e muitos triviais". Dos 24 parâmetros analisados (expressos na legenda da Figura 2), em oito destes estão $79 \%$ das ocorrências.

Analisando separadamente cada um dos parâmetros encontrados, os que apresentaram mais ocorrências (apareceram com 275 e 272) foram os entulhos de construções e o lixo 
doméstico espalhado pelas ruas, respectivamente. Em termos percentuais, os dois parâmetros apresentaram 18\% da ocorrência, cada um. Alves et al. (2004) mencionam que existe uma correlação direta entre esses dois tipos de deposição, sendo que a deposição de resíduos de construção influencia para que residentes do entorno e carroceiros depositem os resíduos domésticos e outros, funcionando, assim, certos locais como pontos de "atração".

Figura 2 - Número de ocorrência de problemas ambientais em logradouros de Itapetim expressos em valores absolutos e acumulados, 2015.

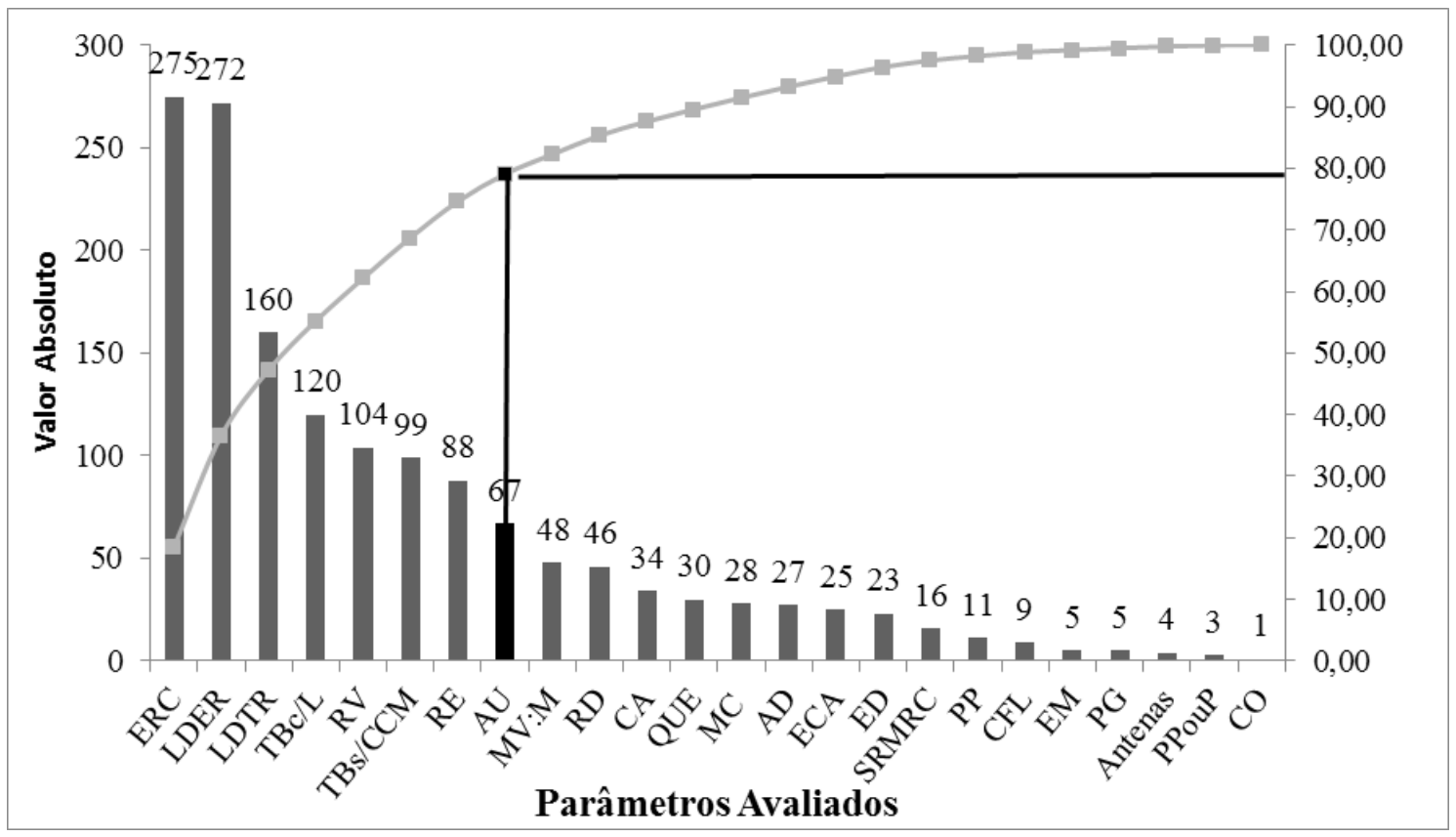

Legenda: ERC - entulhos de restos de construções; LDER - lixo doméstico espalhado nas ruas; LDTR - lixo doméstico transbordando de recipiente; $T B c / L$ - terreno baldio com lixo; $R V$ - resíduos vegetais; $T B s / C C M$ - terreno baldio sem cerca ou cuidados de manutenção; RE - rede elétrica (poluição visual); AU - arborização urbana deficiente; $M V: M$ materiais volumosos: mobiliários; $R D$ - rua deteriorada; $C A$ - criatório de animais; $Q U E$ - queimadas; $M C$ - materiais de comercialização ou de construção depositados em ruas ou calçadas; AD - animais domésticos; ECA - esgoto a céu aberto; ED - edificações deterioradas; $S R M R C$ - secção de rios, margens de rios e canais deteriorados; PP - propaganda política; CFL - camelôs e feiras-livres; EM - estábulos e matadouros; PG - poluição gasosa; Antenas - antenas de celulares, internet etc.; PPouP - poluição pó elou partículas; $C O$ - cartazes e outdoors.

Fonte: Elaborada pelos autores, 2015.

Em seguida, os parâmetros que apresentaram maiores incidências (com os respectivos percentuais de ocorrências), entre aqueles já apontados como principais, foram: lixo doméstico transbordado de recipientes (10,7\%); terreno baldio com lixo (8\%); resíduos vegetais $(6,9 \%)$; terreno baldio sem cerca e sem cuidados de manutenção $(6,7 \%)$; rede elétrica aérea $(5,9 \%)$ e arborização urbana deficiente (4,5\%). Dessa forma, se observa que só a questão dos resíduos é responsável por $60,9 \%$ dos problemas de Itapetim. Isto ocorre mesmo com a coleta diária de resíduos por parte da prefeitura. Alves et al. (2004), em

D 
Teixeira (PB); Sousa (2006), em Água Branca (PB), e Nóbrega (2007), em Coremas (PB), também encontraram os mesmos problemas observados em Itapetim.

Outro problema ali encontrado, que acaba tendo relação indireta com os resíduos, é a presença de animais domésticos, como, por exemplo, cachorros abandonados ( $1,8 \%$ dos problemas) que estão vivendo de forma livre pela cidade e rasgam os recipientes à procura de comida, agravando ainda mais o problema do lixo com a sua dispersão de forma difusa. Isto se dá por causa da insistência dos residentes de depositarem nas calçadas os recipientes de lixo em horários distantes da hora da coleta pela prefeitura. Vale ressaltar que os garis só recolhem o lixo que se encontra dentro de sacos ou baldes, e o lixo que se espalha no chão não é recolhido.

Como consequência disso, a população começa a se incomodar com os odores provenientes dos resíduos e dos animais e passa a utilizar os terrenos baldios e as construções abandonadas para depositar ali o seu lixo. Mucelin et al. (2008) observaram, em seu trabalho, o hábito das pessoas de utilizarem esses locais para a deposição de resíduos sólidos, o que atrai animais domésticos (bovinos, caprinos, asininos, equinos, caninos e felinos) e vetores (ratos, baratas, mosquitos) que transmitem doenças. Outra agravante dessa questão é o fato de que os residentes que não possuem terras rurais criam animais de tração e de produção nas periferias da cidade, sendo que muitos utilizam lotes de terceiros, o que gera conflitos, além de problemas ambientais.

A arborização da cidade não é adequada e apresenta pouca variação de espécies. A maioria desta vegetação é exótica, como a Azadirachta indica (nim indiano), a Senna seamea (cássia siamea) e a Terminalia catappa (castanhola), sobre as quais não foram realizados estudos acerca do solo, da adaptação destas espécies e das questões ecológicas que podem afetá-las com a sua introdução no município. Na arborização urbana correta, não se recomenda monocultura, e, sim, a utilização de diversos espécimes, com a finalidade de se manter uma boa estética (DANTAS, SOUZA 2004).

A árvore, no meio urbano, melhora a qualidade de vida das pessoas, desempenhando funções diversas (como o controle da temperatura ambiental e da poluição), auxiliando no conforto térmico, na estruturação dos espaços nas ruas e praças, nos ciclos ecológico e hidrológico, além de estarem presentes na proteção do solo, conforme asseveram Gonçalves e Paiva (2004) e Dantas e Souza (2004). No entanto, não se verificam, em Itapetim, os cuidados necessários para a escolha, o plantio e a manutenção da arborização. 
Observa-se que tanto a população como os gestores públicos estão negligenciando as questões ambientais dessa cidade, e, nesse sentido, há a necessidade de se investigar por que isto ocorre. Assim, em sequência, serão discutidos os resultados das entrevistas realizadas nesta pesquisa.

\section{O conhecimento sobre a existência e o funcionamento de leis e da infraestrutura relacionadas às questões ambientais de Itapetim}

Uma cidade é gerida com base em leis e códigos que são elaborados para que haja ordem, crescimento e desenvolvimento, no entanto, muitos gestores encobrem e/ou não põem em prática essas normas. Mediante isto, se também a população não age de forma cidadã, ela e o meio ambiente são os mais prejudicados.

Pelas respostas dadas à presente pesquisa por parte da população, dos legisladores e do representante do poder executivo de Itapetim, foram demonstradas contradição e falta de conhecimento sem precedentes. Entre os residentes, 70\% não souberam responder ou não sabiam se existe uma Secretaria de Meio Ambiente em sua cidade (Tabela 1).

\section{Tabela $1 \otimes$ Comparação das respostas oriundas da população e dos gestores de Itapetim com} relação às questões administrativas.

\begin{tabular}{c|c|c|c|c|c}
\hline Parâmetros & População & & $\begin{array}{c}\text { Legisladores e } \\
\text { representante } \\
\text { do executivo }\end{array}$ \\
\hline $\begin{array}{c}\text { Conselho Municipal } \\
\text { de Meio Ambiente }\end{array}$ & 34,29 & 21,43 & 44,29 & 0 & 100 \\
\hline Plano Diretor & 14,29 & 25,71 & 60,00 & 0 & 100 \\
\hline Lecretaria de Meio Ambiente & 30,00 & 38,57 & 31,43 & 0 & 100 \\
\hline $\begin{array}{c}\text { Lei de Uso e Ocupação do Solo } \\
\text { do Solo Urbano }\end{array}$ & 41,43 & 11,43 & 47,14 & 100 & 0 \\
\hline Lei Orçamentária & 42,86 & 8,57 & 48,57 & 100 & 0 \\
\hline Código Tributário & 47,14 & 5,71 & 47,14 & 100 & 0 \\
\hline
\end{tabular}

D

D D 


\begin{tabular}{|c|c|c|c|c|c|}
\hline Parâmetros & 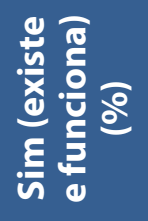 & 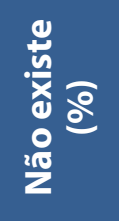 & 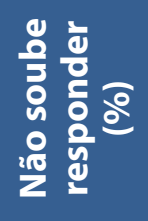 & 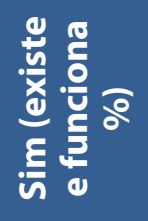 & 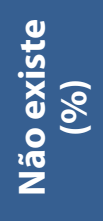 \\
\hline Código de Obras & 48,57 & 5,71 & 45,71 & 100 & 0 \\
\hline Código de Posturas & 42,86 & 8,57 & 48,57 & 100 & 0 \\
\hline $\begin{array}{l}\text { Legislação ambiental } \\
\text { no município }\end{array}$ & 34,29 & 22,86 & 42,86 & 0 & 100 \\
\hline Cadastramento urbano & 58,57 & 4,29 & 37,14 & 100 & 0 \\
\hline $\begin{array}{c}\text { Estação de tratamento } \\
\text { de esgoto }\end{array}$ & 27,14 & 34,29 & 38,57 & 0 & 100 \\
\hline Rede de esgoto & 42,86 & 20,00 & 37,14 & 100 & 0 \\
\hline Estação de tratamento de água & 75,71 & 10,00 & 14,29 & 100 & 0 \\
\hline $\begin{array}{l}\text { Destino final dos } \\
\text { resíduos sólidos }\end{array}$ & 38,57 & 38,57 & 22,86 & 30 & 70 \\
\hline $\begin{array}{c}\text { Destino final dos resíduos } \\
\text { hospitalares }\end{array}$ & 27,14 & 32,86 & 40,00 & 100 & 0 \\
\hline
\end{tabular}

Fonte: Elaborada pelos autores, 2015.

Durante as entrevistas, observou-se que há confusão quanto ao entendimento do papel de uma Secretaria de Meio Ambiente e de secretarias da Cultura e da Saúde, ou seja, muitos entrevistados acreditam que estas têm as mesmas competências e que executam as mesmas atividades. Igualmente, existem as mesmas dúvidas quanto a diversas outras leis e infraestrutura da cidade. Portanto, conforme as respostas observadas na Tabela 1, há falta de conhecimento sobre esses temas, bem como também a inexistência de diversas leis, nesse município.

Com base nos trabalhos consultados e referenciados neste artigo, sabe-se que, em qualquer cidade, inclusive nas pequenas, o desconhecimento ou mesmo o desinteresse da população sobre esses temas podem gerar problemas para a sociedade e para os recursos naturais que a circundam. Vale ressaltar que a população não sabia do que tratavam algumas questões levantadas na entrevista, no entanto, já ouviram falar sobre alguns termos utilizados no questionário, por meio de programas e jornais de televisão ou mesmo de discursos realizados em campanhas eleitorais. Como exemplo disto,cita-se o Plano Diretor, que é uma lei municipal elaborada e composta com a participação dos cidadãos, pois deve conter explicitamente o projeto de uma cidade desejada por todos e de como seria o seu 
desenvolvimento. Neste caso, Itapetim não tem um Plano Diretor, porque tem população inferior a vinte mil habitantes, não sendo obrigado por lei a implantá-lo, embora devesse, tendo em vista que esta seria uma grande diretriz para o desenvolvimento da cidade.

Esse tipo de informação não é abordado nas escolas de ensino regular, e a população desconhece a sua existência e importância. Isto pode explicar o fato de $60 \%$ dos entrevistados não saberem responder sobre o Plano Diretor (se tinha ou não) e de que os que mencionaram algo a respeito deste plano não souberam justificar a sua resposta.

Para Philippi Jr. et al. (1999), os municípios brasileiros, obedecendo às leis de caráter estadual e federal, podem decidir quais os meios de proteção sobre o seu patrimônio natural ou cultural. No entanto, em Itapetim, se pode constatar que os seus gestores não fazem investimentos visando à proteção do meio ambiente, visto que não apresentam legislação ambiental e nem sequer Secretaria de Meio Ambiente, entre outras iniciativas necessárias.

Segundo os administradores e/ou representantes, existem alguns códigos e leis nessa cidade, mas a Secretaria de Meio Ambiente, o Conselho Municipal de Meio Ambiente, o Plano Diretor e a estação de tratamento de esgoto ainda são ali inexistentes. Contudo, houve divergência nas respostas quanto ao destino final dos resíduos sólidos, pois esse município possui um "lixão" a céu aberto, na zona rural. Verifica-se que 30\% dos representantes públicos consideraram essa forma de descarte de lixo urbano como correta, enquanto $70 \%$ responderam que este tipo de descarte não existia na cidade. Mas sabe-se que, de fato, esta não é a maneira certa de deposição de resíduo urbano.

As respostas dos entrevistados demonstram que essa população desconhece como está sendo a administração municipal e não questiona certas medidas tomadas na cidade, bem como se mostra acomodada à situação existente, já que não se observa, de sua parte, nenhuma ação proativa.

A situação da cidade de Itapetim é reflexo inconteste daquilo que Mendonça (2004) afirma sobre a inocuidade das políticas públicas no ordenamento territorial, o que culmina no esquecimento dos problemas socioambientais, sendo que estes problemas estão ligados ao modelo de desenvolvimento, que tem, nos dias de hoje, um dos seus pilares assentados no consumo.

D

D Devista da Associação Nacional de Pós-graduação e Pesquisa em Geografia (Anpege).

$D^{D}$ p.6-30, V.15, n.27, mai./ago. 2019. 


\section{Conhecimento e percepção da população sobre os problemas ambientais da área urbana da cidade de Itapetim}

\section{Perfil socioeconômico dos entrevistados}

Os entrevistados nesta pesquisa eram residentes em Itapetim havia mais de cinco anos, sua faixa etária variava entre 20 e 68 anos, e 44\% deles tinham concluído ou estavam cursando o ensino médio. Nos dois extremos de escolaridade, $5 \%$ dos entrevistados eram analfabetos e $21 \%$ tinham ou estavam cursando o ensino superior.

A economia dessa cidade está baseada no comércio e nos serviços públicos: $27,6 \%$ da população entrevistada são de servidores públicos municipais, estaduais ou federais, seguidos de um percentual de $23,4 \%$ de aposentados. As demais fontes de renda são: o comércio (15,2\%), os autônomos (12,4\%), a agricultura (8\%) e outras (13,2\%). Vale salientar que, apesar de 39\% dos moradores serem da zona rural, sua renda familiar não provém da agricultura, como pôde ser observado anteriormente.

\section{Conhecimento e percepção dos problemas ambientais pelos entrevistados}

Dentro do contexto supracitado, para despertar a curiosidade e o interesse dos entrevistados, foram elaboradas perguntas sobre temas relacionados ao meio ambiente, com o intuito de avaliar como se expressa a sua percepção acerca destes problemas e o grau de conhecimento de conceitos adjacentes. O primeiro questionamento foi se o entrevistado sabia o que era poluição. Verificou-se que os entrevistados tinham uma ideia de poluição como algo que atinge e/ou prejudica o solo, a água e/ou o ar, dependendo do tipo de poluente, e, por consequência, prejudica a saúde pública: $82 \%$ se referiram a poluições diversas como fumaça, queimadas, lixo, sujeira, água contaminada, poluição visual e sonora, esgoto a céu aberto e dejetos; outros 13,9\% se referiram à degradação ambiental na cidade; e houve, ainda, respostas sobre a poluição relacionada a desmatamento e animais nas ruas. Somente $1,6 \%$ disseram que não sabiam responder.

O percentual elevado de referências a elementos da poluição pode ter sido influenciado por diversos fatores, como, por exemplo, a obtenção destas informações nos meios de comunicação. Em Itapetim, a frota de veículos não é tão grande, as fábricas e indústrias são inexistentes, mas, no entanto, a cidade apresenta padarias e pizzarias cujos fornos não possuem filtros de fumaça, e, como consequência disto, a população do entorno se sente 
incomodada com a dificuldade de respirar causada por excesso de fumaça na atmosfera. Então, é muito provável que suas respostas estejam relacionadas a esta fumaça que vem das redondezas.

Quanto ao lixo, aspecto que pode gerar incômodo nas relações entre vizinhos, na saúde, no bem-estar e no conforto da população, assim como nos recursos hídricos e no meio ambiente da cidade, este é um problema que se torna facilmente percebido pelo cidadão comum. Este aspecto é muito controverso, pois as pessoas se referem a tal assunto, quando questionadas, contudo, autores como Horgan (2007), Alves et al. (2004) e Alves (2013) relatam que este fato não implica em ações por parte da população, que acaba sofrendo com o problema que ela mesma causa. No seu cotidiano, a problemática do lixo acaba passando despercebida.

A água contaminada pode ter sido lembrada pela presença de uma barragem existente na área urbana da cidade, situada numa microbacia hidrográfica, com presença de efluentes poluidores em seu interior e ausência de manutenção. Este manancial poderia ser utilizado para o consumo das pessoas e nos afazeres domésticos, mas se apresenta apenas como um depósito de dejetos. Outros estudos apresentam problemas semelhantes aos da existência de mananciais dentro de áreas urbanas, como os de Rodrigues et al. (2009) e Alves et al. (2012), que mostram os impactos causados por efluentes domésticos despejados dentro desses corpos d'água. Itapetim também é cortada por um canal coletor de águas pluviais que funciona como escoadouro de esgotos domésticos, contribuindo, assim, para a percepção deste problema pelos residentes.

A educação ambiental, nas escolas da cidade, ainda é incipiente, pois os entrevistados conseguiram fazer algumas correlações entre a problemática ambiental e alguns conceitos sobre meio ambiente, poluição etc., embora distorcidas e/ou descontextualizadas. É provável que a mídia também possa estar sensibilizando as pessoas e influindo em suas respostas, porque as pessoas tendem a acreditar em tudo que é informado, tantos em redes sociais como em canais de televisão e de internet, onde ocorrem alguns enganos e nem sempre as informações são transmitidas de forma correta - no entanto, esta é apenas uma hipótese aventada pelos autores deste artigo. As escolas de ensino regular da cidade promovem eventos pontuais sobre o Dia do Meio Ambiente, abordando temas como reciclagem, poluição diversa e recursos hídricos, e, dessa forma, podem também estar impactando, de forma positiva, a percepção da população quanto a estes problemas. Mas, apesar das respostas acima mencionadas, parte significativa dos entrevistados não soube responder sobre o que é poluição.

D 
A segunda pergunta feita no questionário foi: “o que é meio ambiente?" Neste aspecto, $41 \%$ dos entrevistados tinham uma visão de que o meio ambiente está relacionado aos elementos da natureza, como a fauna, a flora, o solo e a água, ou seja, ainda possuíam uma visão romântica e naturalista, ignorando o ser humano como parte integrante do meio. Esta mesma concepção naturalista foi observada por Mota et al. (2013), ao fazerem um estudo com catadores de resíduos sólidos, em que $42 \%$ das pessoas, quando falavam em meio ambiente, ligavam este tema a elementos da natureza.

Para 34\% dos entrevistados de Itapetim, o lugar onde se vive é conceito de meio ambiente, considerando a casa e a cidade como um lugar que se possa utilizar como moradia. Esta concepção de ambiente é antropocêntrica, ou seja, concebe o meio com função utilitarista. Outros entrevistados (18\%) não souberam responder e 6\% deles corresponderam o meio ambiente a outros assuntos.

O termo ecologia foi usado, pela primeira vez, por Haeckel, em1869, definindo-o como o estudo científico das interações entre organismos e o ambiente por estes habitado (BERGON et al., 2007). Definida por esse discípulo de Charles Darwin, ecologia é a ciência que consegue compreender a relação entre os organismos e o seu ambiente (TOWNSEND et al., 2010). Pode-se observar que a definição de ecologia, em princípio, é simples de se responder, no entanto, se trata de um tema com diversas variáveis que são analisadas separadamente e sob fundamentação teórica e que podem causar confusões quando não são abordadas corretamente.

Da população entrevistada, segundo os dados obtidos para a pergunta "o que é ecologia?", 39\% não souberam responder - o que pode ter ocorrido porque se trata de um termo técnico (ecologia) que requer uma base de conhecimento prévio. Muitas vezes, esse conceito não é abordado corretamente nas escolas, o que suscita dúvidas. Dos entrevistados, outros 34\% correlacionaram ecologia com natureza e meio ambiente, citados de forma simultânea. Por outro lado, $8 \%$ dos entrevistados citaram que ecologia era a relação entre os seres vivos e o meio ambiente (estes foram os que se aproximaram mais das respostas da literatura), e $7 \%$ citaram o estudo dos ecossistemas e dos sistemas vivos. Ainda nas respostas sobre o que seria ecologia, $2 \%$ mencionaram: preservação, conservação/evolução e tecnologia/não jogar lixo. Houve uma discrepância em 6,7\% dos entrevistados, que citaram medicina, biologia e estudo da vida.

Essa falta de entendimento e a confusão entre os termos meio ambiente, ecologia e natureza foram observadas por Nóbrega (2007). Ele percebeu, analisando a população de Coremas (PB), que havia uma coesão entre esses termos, levando a um entendimento de 
que seriam sinônimos. Dessa, forma, observa-se uma falha nos processos educacionais ao se trabalhar essa temática, na região, assim como o que é passado pelas mídias não tem o impacto desejado. O fato é que esses termos não fazem parte da linguagem cotidiana das pessoas em geral, demonstrando a dificuldade de se construir uma nação ambientalmente sustentável.

A população entrevistada se mostrou preocupada com a questão dos animais vagando pelas ruas, sendo que apenas $2 \%$ desta não demonstraram preocupação ou a noção de que poderia haver qualquer tipo de problema relacionado a isto. Para 39\% dos entrevistados, os animais podem gerar acidentes, e 31\% responderam que podem ser causadores e/ou vetores de doenças. Ainda houve aqueles (18\%) que citaram o aparecimento de sujeira e de problemas de irritação, aborrecimento e incômodo devido aos animais de rua. Isto já foi verificado por Sousa (2006), na cidade de Água Branca (PB).

Para o parâmetro encontrado em maior percentual na área urbana, que foram os entulhos espalhados pelas ruas, $38 \%$ dos entrevistados acharam que esta era uma prática errada e que deveria ser proibida. Para 20\% dos entrevistados, depositar entulhos na rua se torna um atrativo para as pessoas também depositarem seus resíduos juntos a estes, fazendo com que ocorra o surgimento de animais vetores e causadores de doenças, gerando problemas para saúde da população. Tais respostas são corroboradas pelas referências da literatura, já citadas neste artigo. Há também aqueles que mencionaram esse como um problema de interferência no trânsito (17\%), podendo ocorrer acidentes por causa do lixo nas ruas. Para 7\% dos entrevistados, a solução seria a retirada dos entulhos, seja pela ação da prefeitura ou pela população, mas que o lixo não deveria ser deixado na rua; 9\% dos entrevistados acusavam a questão do lixo à falta de educação e de respeito com a vizinhança; e 6\% destes apresentaram preocupação com problemas futuros, como o arraste dos entulhos para os rios e bueiros, que poderiam ser entupidos, gerando enchentes na ocorrência das chuvas.

Como foram encontradas grandes quantidades de monturos contendo resíduos de construções, nas ruas de Itapetim, os gestores municipais poderiam seguir as recomendações de Santos (2015), entre as quais se destacam o incentivo à segregação e aos cuidados para cada tipo de resíduo e sua destinação ambientalmente correta. Nesse sentido, adotar essas práticas poderá permitir o reaproveitamento dos entulhos que ainda podem ter finalidades específicas na própria construção, bem como o seu uso em outros setores.

Verificou-se a opinião das pessoas entrevistadas sobre cartazes, outdoors e propagandas colocadas em ruas, esquinas e terrenos baldios. Para $46 \%$ dos entrevistados, não houve problema algum, e 14\% destes acreditavam que este meio de comunicação era bom para

D 
a divulgação de eventos e/ou a comercialização. No entanto, 10\% achavam errada essa prática e 14,6\% pensavam que esses meios de comunicação poderiam tirar a atenção dos motoristas e, consequentemente, gerar problemas-como, por exemplo, acidentes de trânsito. Somente $11 \%$ acharam que esse meio de comunicação era poluição visual.

Outro meio de divulgação muito utilizado, nas cidades do interior do Nordeste brasileiro, é o uso de carros comuns ou adaptados com equipamentos de som (muitas vezes, de intensidade muito elevada). Identificou-se que $74 \%$ dos entrevistados alegaram que isto causa incômodo e é uma prática errada, pois muitos desses carros não respeitam o volume permitido e, muito menos, os locais indevidos para este tipo de divulgação (perto de hospitais e igrejas). Apenas $8 \%$ disseram que era poluição sonora.

Direcionando o enfoque da pesquisa para a questão da arborização e dos serviços urbanos, procurou-se saber dos entrevistados o que eles pensavam a respeito da arborização, dos serviços de limpeza urbana e de outras questões gerais. Foram obtidas as seguintes respostas: para 45\% dos entrevistados, o maior benefício da arborização é a presença de sombra; e $11 \%$ se referiram à melhoria das condições estéticas da cidade (embelezamento) e de conforto térmico.

A vivência no dia a dia de uma cidade do semiárido brasileiro também traz alguns aspectos interessantes, pois $8 \%$ dos entrevistados relacionaram a presença de árvores com a chuva; $1 \%$ se referiu à produção de oxigênio; e 3\% a relacionaram a questões respiratórias. Porém, sabe-se que, em nível local e em pequenas áreas, dificilmente as plantas influenciam a precipitação, nesse local. Por outro lado, uma das maiores contribuições das árvores, além daquelas já percebidas pelos entrevistados, é a produção de oxigênio, com pouquíssima referência (1\%).

Os benefícios da arborização são mencionados por Preissler (2011) e Oliveira et al. (2013), que citam a introdução de espécies arbóreas como fator importante para o resfriamento em regiões de clima quente, e que o sombreamento proporcionado por suas copas evita a entrada dos raios solares, fazendo com que as temperaturas sejam mais amenas embaixo das árvores. E quanto mais árvores, melhor será o conforto térmico daquele local.

Quanto aos serviços de limpeza pública, de grande importância para a vida da população, constatou-se que $86 \%$ da população entrevistada responderam que a limpeza urbana não é obrigação apenas da prefeitura, sendo os cidadãos também responsáveis por manter a cidade limpa. Por outro lado, ainda assim, 12\% acreditavam que apenas a prefeitura é responsável pela limpeza urbana, e que a população deve se preocupar apenas 
com a limpeza de suas casas, pois o lixo urbano não é preocupação dos moradores, mas, sim, dos governantes.

Questionou-se sobre os serviços de limpeza prestados pela prefeitura, como também sobre a organização referente à coleta de lixo, à varrição, à capinação e à manutenção dos meios-fios. Os percentuais das respostas obtidas foram: $56 \%$ responderam que esses serviços são bons; 20\%, que são regulares; $15 \%$, que são ruins; e 8\%, que são muito bons. Perguntou-se, em seguida "por quais serviços públicos (limpeza e organização) a prefeitura é responsável"? Mesmo que as pessoas presenciassem diariamente a coleta de lixo na cidade, ainda assim, não souberam dizer que a prefeitura era a responsável por este serviço, e 30\% não sabiam de nenhum serviço prestado pela prefeitura e seus responsáveis. Muitos responderam se remetendo a questões políticas e até citaram nomes de candidatos, afirmando que as condições atuais eram ou não responsabilidade do atual governo. Dos entrevistados, $60 \%$ citaram a coleta de lixo e $6 \%$ citaram a poda de árvores e a manutenção de praças e de meios-fios como serviços prestados pela prefeitura.

Já os serviços de limpeza e a organização prestada pela prefeitura foram confundidos por 3,8\% da população entrevistada, que se referiu à infraestrutura, à educação, à saúde, ao saneamento básico e às construções civis. Aqueles que não sabiam de serviços nenhum, mais uma vez, se pronunciaram a respeito de partidos políticos, e não levaram em consideração que, independentemente de candidatos, o gestor que representa o povo dessa cidade tem que cuidar e zelar pelas questões ambientais.

A população entrevistada, mesmo não apresentando base teórica de conhecimento sobre o meio ambiente, ao ser questionada sobre se deveria haver multas para quem fosse pego prejudicando o meio ambiente e se estaria disposta a pagar esta multa ou a agir como agente/fiscal (ou seja, denunciar quem prejudica o meio ambiente), 100\% dos entrevistados responderam que sim para ambas as perguntas. Afirmou-se que deveria haver fiscalização e multas, contudo, de forma contraditória e sem perceber, a população critica os outros, quando o problema é de todos.

Por último, foi solicitado aos entrevistados que citassem três dos principais problemas ambientais da sua cidade, em ordem de importância: 34\% das pessoas afirmaram que era o "lixão"; 12\%, o lixo na rua; e 10\%, a seca. Este último problema pode ser explicado devido à crise hídrica vivenciada pela população dessa região, nos últimos cinco anos (2011 a 2015). Percebe-se, mais uma vez, a preocupação da população com relação ao destino final do lixo da cidade, no entanto, não se procura saber quais são as medidas tomadas pelos gestores.

D D Devista da Associação Nacional de Pós-graduação e Pesquisa em Geografia (Anpege).

D D p.6-30, V.15, n.27, mai./ago. 2019. 
O lixo, questão que faz parte do cotidiano dos citadinos, passa a ser mais percebido, porque se encontra em grande quantidade, espalhado em terrenos baldios e no próprio "lixão", e estes espaços se tornam indesejáveis, conforme assevera Rodrigues (1998), de forma que vêm sempre à mente do interlocutor quando este é desafiado a falar sobre o assunto.

Verifica-se, a partir das informações levantadas, como emerge a problemática socioambiental de uma cidade de pequeno porte - que, de certa forma, não difere de muitas cidades grandes, mudando somente o contexto e a magnitude dos problemas. Demonstra-se a inocuidade de políticas públicas voltadas para uma educação ambiental de fato, pois há desinformação, desconhecimento e falta de comprometimento da população para com as questões ambientais, embora ressoem alguns aspectos positivos daquilo que a população pensa a respeito de seus problemas ambientais. Assim, há muito que se fazer para reverter o quadro observado. Na mesma perspectiva, verifica-se também a total ignorância dos legisladores e do executivo municipal no que concerne à formulação da própria legislação urbanística, que poderia nortear a cidade de Itapetim para um desenvolvimento mais harmonioso entre a sociedade e o ambiente e, quiçá, para a execução das parcas leis que ali existem.

Pode-se observar que os principais problemas constatados em Itapetim têm a ver com a questão dos resíduos sólidos, que são abundantemente encontrados nos interstícios desta cidade. Ou seja, mesmo nas pequenas cidades do interior, a produção do espaço está sob forte influência dos elementos econômicos, conforme constata Carlos (2011), pois, de forma generalizada, o lixo se espalha por terrenos baldios, calçadas e ruas. Este lixo abundante é fruto das forças produtivas modernas, por meio das quais uma quantidade e variedade enormes de novos produtos, dotados de novas tecnologias, são produzidas e ofertadas à população, que as consome vorazmente, estimulada pelo marketing e até mesmo por gestores públicos que vão às mídias incentivar o seu consumo para se "salvar a economia". Quase sempre, esses produtos são descartáveis, pois, além da baixa qualidade, muitos já vêm com a obsolescência programada, feitos para serem usados por curto espaço de tempo.

Tudo isso provoca um "frenesi" de consumo, pois as novas mídias e os sistemas de comunicação, aliados às técnicas de marketing, promovem o "ciclo" da moda, em curtos espaços de tempo. Dessa forma, há a percepção de que o tempo encolhe e de que tudo ocorre muito rápido, e isto leva o rebatimento de tais percepções ao espaço, que passa a quase não ser percebido, ou seja, se torna “ocultado", conforme Rodrigues (1998). Nesse sentido, confirma-se a citação de Santos (2006, p. 132) sobre a ideia de um espaço suprimido pela "interpretação delirante do encurtamento das distâncias". 
Nessa mesma seara, na rotina e nos afazeres do dia a dia - ou seja, nas ações, em que se segue a máxima "tempo é dinheiro" -, as pessoas acabam se esquecendo ou não percebendo o espaço onde vivem, passando a não mais perceber os problemas da cidade, que se tornam "normais", não se dando a eles a devida atenção. Conforme Santos (2006) menciona, há uma indissociabilidade entre objetos e ações - mas estes são indissociáveis -, e o espaço ocupado, imerso numa série de externalidades socioambientais, passa despercebido pela maioria. Cria-se, nesse processo, um "ciclo vicioso" de normalidade, do que não deveria ser normal, portanto, não há mudanças no sentido de se tornar melhor as coisas do lugar, o que está em conformidade com uma célebre frase de Santos (2006, p. 51): "As ações são cada vez mais estranhas aos fins próprios do homem e do lugar".

O espaço da cidade, o espaço da cidadania, o espaço da produção econômica, o espaço onde se manifesta o modelo de economia vigente, por meio da grande quantidade de resíduos em seu interstício, entre outros problemas ambientais, se encontra "maltratado", "desprezado", e onde a própria população, contraditoriamente, assume a sua responsabilidade ao mesmo tempo em que assiste, de forma passiva, a sua tecnoestrutura e a sua psicosfera se deteriorando, de certa forma. Ressoam, assim, no espaço de uma cidade do interior do Nordeste, "os ventos" de uma sociedade globalizada consumista, importando apenas as relações econômicas, à procura de sobrevivência em uma região de clima hostil.

\section{Considerações finais}

A cidade de Itapetim apresenta uma série problemas ambientais, que não recebem a devida atenção por parte dos seus legisladores e executivo. Os gestores desta cidade não se preocupam com as questões ambientais abordadas, pois permitem que se construa em áreas de margens de rios, não apresentam um local correto de despejo dos resíduos sólidos e líquidos, não apresentam uma solução para o controle de animais domésticos nas ruas, não proporcionam serviços de coleta de entulhos e não apresentam pessoal capacitado para implantar, cuidar e manter a arborização da cidade, entre outras falhas.

A amostra da população entrevistada apresentou um grau de escolaridade relativamente bom. Mesmo assim, ainda existe uma falta de programas ou de projetos que visem ao bem-estar do e no meio ambiente e à sua manutenção/conservação, como, por exemplo, a conscientização e a educação ambiental nas escolas públicas.

No que concerne às questões ambientais, o conjunto de respostas da população amostrada permite inferir que há falhas no processo de educação ambiental, seja esta formal ou informal, que lhe possibilitaria ter uma melhor compreensão sobre estas questões, bem

D 
como participar e cobrar dos gestores públicos uma melhor gestão ambiental da sua cidade. Essas pessoas demonstraram não saber (ou nem procuraram saber) sobre os projetos e ações realizadas pela prefeitura. Seria interessante se a população participasse ativamente das decisões tomadas na Câmara de Vereadores e opinasse sobre elas.

A população que participou desta pesquisa apresentou preocupação com a presença do "lixão" na cidade. Também identificou que havia lixo, animais, entulhos e poluição visual e sonora nas ruas e um "lixão" irregular. Há, de certa forma, alguma preocupação com a degradação do meio ambiente, uma vez que todos os entrevistados estavam disponíveis para trabalhar como agentes fiscalizadores ambientais. No entanto, contraditoriamente, estes cidadãos "assistiam", de forma passiva, o desenrolar do cotidiano de suas próprias ações no espaço urbano, onde emerge uma série de externalidades ambientais e predomina um "desajuste" nos sistemas de objetos e ações.

Observa-se que, na convivência entre sociedade e ambiente no espaço urbano, em Itapetim, transparece uma normalidade, contudo, verificam-se conflitos, e tal fato tem mais a ver com a falta de uma percepção "mais aguçada” acerca da problemática ambiental, em decorrência de um grau superficial de conhecimento entre causa e efeito (ações humanas e impactos ambientais). Assim, as relações entre sociedade e ambiente estão ocorrendo de forma em que ambos perdem, pois a situação pró-ambiente é desfavorável, e, num ambiente impactado negativamente, uma série de problemas sociais de curto, médio e longo prazos pode emergir.

\section{Referências bibliográficas}

1. ALVES, T. L. B.; LIMA, V. L. A.; FARIAS, A. A. Impactos ambientais no rio Paraíba na área do município de Caraúbas/PB: região contemplada pela integração com a bacia hidrográfica do rio São Francisco. In: Revista on line Caminhos de Geografia. Uberlândia, v. 13, n. 43, out/2012, p. 160-173. Disponível em: < http://www.seer.ufu. br/index.php/caminhosdegeografia.php >. Acesso em: 18 setembro de 2015 .

2. ALVES, J. B. Problemática socioambiental da disposição irregular de resíduos sólidos em espaços abertos na cidade de Fazenda Rio Grande/Paraná. Tese (Meio Ambiente e Desenvolvimento). PPG-MADE - Universidade Federal do Paraná, 2013, 385 f.

3. .; SOUTO, J. S.; SILVA, W. A.; LOPES, L. I.; RODRIGUES, C. R. F. Diagnóstico ambiental de rua e bairros de Teixeira/PB. In: Revista Árvore. Viçosa/MG, v. 28, n. 5, p. 755-764, 2004. Disponível em: <http://www.scielo.br/pdf/rarv/v28n5/23415.pdf> Acessado em 20 jul. 2015 
4. BERGON, M. Ecologia: de indivíduos a ecossistemas. Porto Alegre: Artmed, $4^{\mathrm{a}}$ ed., 2007. Tradução: Adriano Sanches Melo.

5. CARLOS, A. F. A. A condição espacial. São Paulo: Contexto, 2011, 157p.

6. DANTAS, I. C.; SOUZA, C. M. C. Arborização urbana na cidade de Campina Grande/ PB: inventário e suas espécies. In: Revista de Biologia e Ciências da Terra, v. 4, n. 2, Campina Grande/PB, 2004. Disponível em: <http://joaootavio.com.br/bioterra/ workspace/uploads/artigos/arborizaurbana-515646a391755.pdf >. Acesso em 03 de fevereiro de 2016.

7. DORST, J. Por uma ecologia política: antes que a natureza morra. Tradução de Rita Buongermino. São Paulo: Edgard Blücher, 1973,1ª ed., 394p.: Título original: Avant que nature meure, pour une écologie politique.

8. GUERRA, A. J. T.; CUNHA, S. B. Impactos ambientais urbanos no Brasil. Rio de Janeiro: Bertrand Brasil, 2001, 416p.

9. GONÇALVES, W.; PAIVA, H. N. Árvores para o ambiente urbano. Viçosa: Editora Aprenda Fácil, 2004, 243 p.

10. HARVEY, D. Espaços de esperança. Tradução de Adail Ubirajara Sobral e Maria Stela Gonçalves. $5^{\text {a }}$ ed., São Paulo: Loyola, 2012, 382p. Título original: Spaces of hope.

11. HORGAN, D. J. Dinâmica populacional e mudança ambiental: cenários para o desenvolvimento brasileiro. Campinas: Nepo/Unicamp, $1^{\text {a }}$ ed., 2007, 240p.

12. IBGE. Instituto Brasileiro de Geografia e Estatística. Censo demográfico - 2010. Histórico do município de Itapetim/PE. Disponível em: < http://www.cidades.ibge.gov.br/xtras/ perfil.php?lang=\&codmun=260770 > . Acesso em: 01 de setembro de 2015 .

13. MARICATO, E. Brasil, cidades: alternativas para a crise urbana. Petrópolis: Vozes, 2001.

14. MENDONÇA, F. et al. Impactos socioambientais urbanos. Curitiba, UFPR, p. 99-128, 2004.

15. MOTA, E. O.; FREITAS, M. M.; FRANÇA, R. R. A percepção dos resíduos sólidos (lixo) na visão dos catadores da lixeira da Terra Dura em Aracaju, Brasil. In: Scire Salutis, Aquidabã, v. 3, n. 1, p. 86-96, 2013. Disponível em: < http://dx.doi.org/10.6008/ ESS2236-9600.2013.001.0008 > Acessado em: 02 de julho de 2015.

16. MUCELIN, C. A.; BELLINI, M. Lixo e impactos ambientais perceptíveis no ecossistema urbano. In: Revista Sociedade \& Natureza, Uberlândia, 20 (1): 111-124, jun. 2008. Disponível em: < http://www.scielo.br/pdf/sn/v20n1/a08v20n1.pdf > Acesso em: 26 de março de 2016.

D 
17. NÓBREGA, M. G. S. Diagnóstico socioambiental do município de Coremas/PB. Apresentado à Unidade Acadêmica de Engenharia Florestal (Monografia), Patos/PB, 2007.

18. OLIVEIRA, A. S.; SANCHES, L.; MUSIS, C. R.; NOGUEIRA, M. C. J. A. Benefícios da arborização em praças urbanas - o caso de Cuiabá/MT. In: Revista Eletrônica em Gestão, Educação e Tecnologia Ambiental, v. 9, n. 9, p. 1900-1915, fev. 2013. Disponível em: <http://cascavel.cpd.ufsm.br/revistas/ojs-2.2.2/index.php/reget/article/view/7695/ pdf $>$. Acesso em 8 de fevereiro de 2016.

19. PHILIPPI JR, A. F. et al. Municípios e meio ambiente: perspectiva para a municipalização da gestão ambiental no Brasil. São Paulo/SP. Associação Nacional de Municípios e Meio Ambiente, 1999, 201p.

20. PREISSLER, A. A. Arborização urbana pública: benefícios e problemas ambientais. Trabalho de conclusão do curso superior de Tecnologia em Gestão Ambiental (Monografia). Sistema de Ensino Presencial Conectado, Universidade Norte do Paraná, Santa Rosa/RS, 2011. Disponível em: < http://arborizacaoplantasmultifucionais.blogspot. com.br/2011/06/arborizacao-urbana-publica-beneficios-e.htm?m=1>. Acesso em: 19 de set. de 2015.

21. ROCHA, J. S. M. Manual de projetos ambientais. Santa Maria: Imprensa Universitária, 1997, 423p.

22. RODRIGUES, A. M. Produção e consumo do e no espaço: problemática ambiental urbana. São Paulo: Hucitec, 1998, 238p.

23. RODRIGUES, I.; RODRIGUES, T. P.T.; FARIAS, M. S. S.; ARAÚJO, A. F. Diagnóstico dos impactos ambientais advindos de atividades antrópicas na margem do rio Sanhauá e Paraíba. In: Centro Científico Conhecer - Enciclopédia Biosfera, Goiânia, v. 5, n. 8, 2009. Disponível em: < http://www.conhecer.org.br/enciclop/2009B/diagnostico\%20 dos\%20impactos\%20amb.pdf>. Acesso em: 09 de agosto de 2015.

24. SANTOS, M. Metamorfoses do espaço habitado: fundamentos teórico e metodológico da geografia. São Paulo: HUCITEC, 1988,124p.

25. . A urbanização brasileira. São Paulo: USP, $5^{\mathrm{a}}$ ed., 2005, 193p.

26. . A natureza do espaço: técnica e tempo, razão e emoção. $4^{a}$ ed., São Paulo: USP, 2006, 259p.

27. Ensaio sobre a urbanização latino-americana. São Paulo: USP, $2^{\mathrm{a}}$ ed., São Paulo, 2010. 
28. SILVA, M. M. de A.; MEDEIROS, M. J. L.; SILVA, P. K.; SILVA, M. M. P. Impactos ambientais causados em decorrência do rompimento da barragem Camará no município de Alagoa Grande/PB. In: Revista de Biologia e Ciência da Terra, v. 6, n. 1, jun 2006, p. 20-34. Disponível em:< http://docplayer.com.br/325354-Impactos-ambientaiscausados-em-decorrencia-do-rompimento-da-barragem-camara-no-municipio-dealagoa-grande-pb.html >. Acesso em: 18 de set. de 2015.

29. SANTOS, I. R. Medidas para a redução de impactos ambientais gerados pela construção civil. Rio de Janeiro: UFRJ/ Escola Politécnica, 2015, 90 p. Projeto de graduação (Monografia) - UFRJ/ POLI/ Engenharia Civil. Disponível em: $<$ http://monografias. poli.ufrj.br/monografias/monopoli10014319.pdf > Acessado em: 20 set. 2015.

30. SOUZA, D. C. O meio ambiente das cidades. São Paulo: Atlas, $1^{\text {a }}$ ed., 2010, 240p.

31. SOUSA, C. E. D. Diagnóstico socioambiental da cidade de Água Branca/Paraíba. UFCG Monografia apresentada à Unidade Acadêmica de Engenharia Florestal, 2006.

32. TOWNSEND, C. R. Fundamentos em ecologia. Porto Alegre: Artmed, $3^{\text {a }}$ ed., 2010, 576p. Traduzido por Leandro da Silva Duarte. 